\title{
Implementation of the Distribution Requirement Planning Method in Optimizing the Distribution of Packaged Drinking Water Products
}

\section{Implementasi Metode Distribution Requirement Planning Dalam Pengoptimalan Pendistribusian Produk Air Minum Dalam Kemasan}

\author{
Nurlaila Handayani ${ }^{1}$, Yusri Nadya ${ }^{2}$, Dwi Maulana ${ }^{3}$ \\ ${ }^{1,2,3}$ Program Studi Teknik Industri, Fakultas Teknik \\ Universitas Samudra \\ Email address : nurlaila.handayani1984@gmail.com
}

\begin{abstract}
CV Athaya Mineral is an industry that runs its business in the production and distribution of bottled drinking water. At the time of distribution of its products, errors often occur, namely the interpretation of demand data in each distribution chain and information received. The purpose of this study was to determine the optimal lotting technique for the distribution of these products using the Distribution Requirement Planning (DRP) method. From the results of data processing, the retail value of Kede Osa was obtained with a total cost of Rp. 233.696, New Store retail with an amount of Rp. 417,336, retail Ari JP Rp. 99,727, Simpang Remi retail Rp. 165,140, retail Mita Jaya Rp. 619,981. The conclusion of this study is the distribution of the Distribution Requirement Planning method for all Dance products (Glass, Small Bottles, Medium Bottles, and Gallons) to five retailers (Kede Osa, Toko Baru, Ari JP, Simpang Remi, and Mita Jaya) using Economic Order Quantity (EOQ) is a lotting technique with the cheapest distribution costs, except for New Store retailers using the Lot For Lot (LFL) lotting technique.
\end{abstract}

Keywords: Distribution, Distribution Requirement Planning, Lotting Technique, Bullwhip Effect

\section{ABSTRAK}

CV Athaya Mineral adalah industri yang menjalankan usahanya di bidang produksi dan distribusi air minum dalam kemasan. Pada saat pendistribusian produknya sering terjadi kesalahan yaitu interpretasi data permintaan ditiap - tiap rantai distribusi dan informasi yang diterima. Tujuan penelitian ini adalah untuk menentukan teknik lotting yang optimal untuk pendistribusian produk tersebut dengan metode Distribution Requirement Planning (DRP). Dari hasil pengolahan data didapatkan nilai retail Kede Osa dengan total biaya Rp. 233.696, retail Toko Baru dengan sebesar Rp. 417.336, retail Ari JP sebesar Rp. 99.727, retail Simpang Remi Rp. 165.140,retail Mita Jaya Rp. 619.981.Kesimpulan dari penelitian ini adalah pendistribusian metode Distribution Requirement Planning seluruh produk Tari (Gelas, Botol Kecil, Botol Sedang, dan Galon) terhadap lima retail (Kede Osa, Toko Baru, Ari JP, Simpang Remi, dan Mita Jaya) menggunakan Economic Order Quantity (EOQ) merupakan teknik lotting dengan biaya distribusi termurah, kecuali pada retail Toko Baru menggunakan teknik lotting Lot For Lot (LFL).

Kata kunci: Pendistribusian, Distribution Requirement Planning, Teknik Lotting, Bullwhip Effect

\section{PENDAHULUAN}

Distribusi produk jadi perihal yang sangat berarti supaya konsumen merasa puas apabila produk yang di harapkan datang pada waktu yang tepat, kualitas yang bagus, hal ini menyebabkan kebijakan buat pengendalian persediaan produk pada industri sangat berarti dicoba oleh manajemen dalam mengkoordinasi penjadwalan serta perencanaan distribusi dari bagian pemasaran sehingga keuntungan industri senantiasa normal[1] Tujuan ini untuk mencapai tingkat pelayanan pelanggan (customer service level) yang diinginkan pada atau dibawah tingkat ongkos yang telah ditetapkan [2] Pihak- pihak yang ikut serta terlibat dalam pendistribusian produk dari pabrik kepada

Implementasi Metode Distribution Requirement Planning dalam Pengoptimalan Pendistribusian Produk Air Minum dalam Kemasan/ Nur Laila Handayani, Yusri Nadya, Dwi Maulana

Peer reviewed under responsibili of Universitas Muhammadiyah Sidoarjo.

(C) 2021 Universitas Muhammadiyah Sidoarjo. All Right reserved. This is an open access article under the CC BY licence(http://creativecommons.org/licences/by/4.0/ ) 
Prozima : Vol. 5, No. 2, Desember 2021, 73-85

E.-ISSN. 2541-5115

Journal Homepage: http://ojs.umsida.ac.id/index.php/prozima

DOI Link: http://doi.org/10.21070/prozima.v5i2.1531

Article DOI: http://doi.org/10.21070/prozima.v5i2.1531

konsumen hendak membentuk sebuah sistem yang disebut sebagai sistem rantai pasok (supply chain system). Manfaat sistem supply chain merupakan penyedia produk dalam jumlah yang sesuai, keadaan yang tepat, serta pada tempat yang tepat dengan senantiasa membagikan manfaat yang maksimal untuk industry[3] Supply chain adalah jaringan perusahaan-perusahaan yang secara bersama-sama bekerja untuk menciptakan dan menghantarkan suatu produk ke tangan pemakai akhir. Perusahaan-perusahaan tersebut biasanya termasuk supplier, pabrik, distributor, took atau ritel, serta perusahaan-perusahaan pendukung seperti perusahaan jasa logistik[4].

CV Athaya Mineral adalah perusahaan yang bergerak di bidang pembuatan dan penjualan air minum mineral dalam kemasan merk Tari dengan memperhatikan kualitas dan kuantitas produk, mengalami beberapa kesalahan dalam pendistribusian produknya, antara lain kesalahan interpretasi data permintaan di setiap rantai distribusi dan kesalahan informasi yang diterima. Kesalahan ini terjadi karena fluktuasi permintaan yang lebih besar di hulu daripada di hilir. yang disebut fenomena bullwhip effect. Bullwhip effect secara sederhana didefinisikan sebagai fenomena di mana terdapat permintaan yang relatif stabil di tingkat konsumen akhir dan permintaan yang berfluktuasi di rantai pasokan hulu, yang antara lain menyebabkan overstocking, karena sebenarnya permintaan jauh lebih kecil, rencana produksi kacau, fasilitas produksi yang ada tidak digunakan secara optimal[5].

Fenomena bullwhip effect yang terjadi di CV Athaya Mineral dapat dilihat pada Tabel 1, dimana jumlah permintaan yang diterima oleh perusahaan dari tiap - tiap ritel berbeda dengan jumlah yang dibutuhkan oleh pasar atau konsumen.

Tabel 1. Data Penjualan Dan Pemesanan

\begin{tabular}{|c|c|c|c|c|c|c|c|c|}
\hline \multirow{2}{*}{ Periode } & \multicolumn{2}{|c|}{ Tari Gelas (220ml) } & \multicolumn{2}{c|}{$\begin{array}{c}\text { Tari Botol Kecil } \\
(330 \mathrm{ml})\end{array}$} & \multicolumn{2}{c|}{$\begin{array}{c}\text { Tari Botol Sedang } \\
(600 \mathrm{ml})\end{array}$} & \multicolumn{2}{c|}{ Tari Galon (19L) } \\
\cline { 2 - 10 } & Jual(box) & $\begin{array}{c}\text { Pesan } \\
\text { (box) }\end{array}$ & $\begin{array}{c}\text { Jual } \\
\text { (box) }\end{array}$ & $\begin{array}{c}\text { Pesan } \\
\text { (box) }\end{array}$ & $\begin{array}{c}\text { Jual } \\
\text { (box) }\end{array}$ & $\begin{array}{c}\text { Pesan } \\
\text { (box) }\end{array}$ & $\begin{array}{c}\text { Jual } \\
\text { (galon) }\end{array}$ & $\begin{array}{c}\text { Pesan } \\
\text { (galon) }\end{array}$ \\
\hline Aug-18 & 87890 & 88560 & 26590 & 26840 & 26630 & 27400 & 1360 & 1450 \\
\hline Sep-18 & 84380 & 85450 & 28780 & 29100 & 29840 & 29850 & 1370 & 1490 \\
\hline Oct-18 & 84600 & 87400 & 26200 & 26480 & 26170 & 27500 & 1250 & 1420 \\
\hline Nov-18 & 86930 & 87150 & 26120 & 26360 & 26010 & 27900 & 1400 & 1500 \\
\hline Dec-18 & 87430 & 89650 & 27023 & 27277 & 27050 & 27900 & 1420 & 1450 \\
\hline Jan-19 & 86300 & 87780 & 26290 & 26548 & 26300 & 27820 & 1250 & 1450 \\
\hline Feb-19 & 83420 & 86400 & 27040 & 27300 & 27270 & 28040 & 1320 & 1440 \\
\hline Mar-19 & 88080 & 89450 & 28310 & 28560 & 27516 & 28500 & 1360 & 1420 \\
\hline Apr-19 & 84830 & 86000 & 28022 & 28250 & 28150 & 28900 & 1320 & 1400 \\
\hline May-19 & 85370 & 88020 & 27700 & 27990 & 27710 & 29010 & 1340 & 1450 \\
\hline Jun-19 & 84280 & 86000 & 28770 & 29910 & 28860 & 29050 & 1340 & 1480 \\
\hline Jul-19 & 83000 & 85870 & 27460 & 27800 & 27300 & 28700 & 1380 & 1420 \\
\hline Total & 1026510 & 1047730 & 328305 & 332415 & 328806 & 340570 & 16110 & 17370 \\
\hline
\end{tabular}

Sumber: CV Athaya Mineral

Data diatas menyatakan bahwa terjadi perbedaan yang jauh antara jumlah penjualan produk dari retail ke konsumen dan pemesanan produk dari retail ke pabrik, hal ini dikarenakan kesalahan dari interpretasi data permintaan di tiaptiap rantai distribusi, untuk itu perusahaan harus dapat merencanakan pengendalian persediaan produk di gudang guna mengantisipasi adanya permintaan yang berlebih. Salah satu jalan yang bisa ditempuh untuk mengatasi kondisi tersebut adalah menerapkan sistem Distribution Requirement Planning (DRP)

Tujuan sistem distribusi adalah [7]

1. Pelayanan pelanggan:

2. Efisiensi:

3. Investasi inventori minimum:

Implementasi Metode Distribution Requirement Planning dalam Pengoptimalan Pendistribusian Produk Air Minum dalam Kemasan/ Nur Laila Handayani, Yusri Nadya, Dwi Maulana

Peer reviewed under responsibili of Universitas Muhammadiyah Sidoarjo.

(C) 2021 Universitas Muhammadiyah Sidoarjo. All Right reserved. This is an open access article under the CC BY licence(http://creativecommons.org/licences/by/4.0/ ) 
Prozima : Vol. 5, No. 2, Desember 2021, 73-85

E.-ISSN. 2541-5115

Journal Homepage: http://ojs.umsida.ac.id/index.php/prozima

DOI Link: http://doi.org/10.21070/prozima.v5i2.1531

Article DOI: http://doi.org/10.21070/prozima.v5i2.1531

Distribution Requirement Planning (DRP) adalah suatu metode penanganan material yang ditujukan pada proses distribusi barang, baik berupa barang jadi, barang dalam proses maupun barang setengah jadi. DRP mempunya logika yang sama dengan MRP, dimana Bill of Material pada MRP diganti oleh Bill of Distribution pada DRP[6]

Beberapa perubahan yang mungkin akan mempengaruhi rencana DRP adalah[8]

1. Kesalahan peramalan.

2. Perbaikan-perbaikan peramalan.

3. Variasi waktu tunggu.

4. Kehilangan atau kerusakan dari inventori.

5. Pemogokan karyawan/pekerja.

Stok pengaman dalam DRP digunakan untuk mengantisipasi ketidakpastian permintaan relatif terhadap ramalan yang dibuat[9]. Bullwhip effect merupakan fenomena dimana permintaan dari pemasok berfluktuasi tajam dibandingkan penjualan yang mengakibatkan terjadinya distorsi pada tingkat yang lebih tinggi dalam rantai pasok.

Pengurangan bullwhip effect dapat dilakukan jika pihak-pihak dari supply chain memahami penyebabnya. Metode yang dapat digunakan untuk mengurangi bullwhip effect tentunya harus terhubung dengan penyebabnya. Ada beberapa cara untuk mengurangi bullwhip effect dengan berbagi informasi, memperpendek atau mengubah struktur rantai pasok, menurunkan biaya tetap, menciptakan stabilitas harga dan mempercepat waktu pengiriman[10] Terdapat 4 penyebab utama timbulnya bullwhip effect yaitu pembaharuan ramalan permintaan (demands forecast updating), order batching, fluktuasi harga, dan rational \& shortage gaming, besarnya bullwhip effect pada setiap langkah rantai pasok adalah perbandingan antara koefisien variasi pesanan dengan koefisien variasi permintaan[4] Jika nilai bullwhip effect $(\omega)>1$ maka dapat disimpulkan bahwa pada perusahaan tersebut terjadi bullwhip effect [11]

Setelah diketahui nilai bullwhip effect selanjutnya dibuat diagram sebab akibat yang digunakan untuk menganalisis masalah dan faktor-faktor yang menyebabkan masalah tersebut terjadi. Oleh karena itu, diagram ini dapat digunakan untuk menjelaskan penyebab masalah yang berkenaan dengan metode statistik, diagram sebab akibat yang digunakan untuk menggambarkan faktor-faktor penyebab (causes) dan sifat kualitas (akibat) yang ditimbulkan oleh faktor-faktor penyebab tersebut [12]

Ada beberapa prinsip peramalan yang perlu dan diperhitungkan untuk mencapai hasil peramalan yang baik. Prinsipprinsip tersebut adalah sebagai berikut:

Prinsip 1. Peramalan menggambarkan kesalahan (error), hanya akan mengurangi ketidakpastian, tetapi tidak menghilangkannya.

Prinsip 2. Peramalan harus menggunakan titik referensi untuk memprediksi kegagalan, pengguna harus mengetahui ukuran kegagalan yang dapat dinyatakan dalam suatu satuan.

Prinsip 3. Peramalan kelompok produk lebih akurat daripada peramalan hanya satu produk

Prinsip4.Peramalanjangka pendek lebih akurat daripada prakiraan jangka panjang. Prinsip 5.Jika memungkinkan, cobalah untuk menghitung permintaan daripada memperkirakan permintaan.[13]

Metode yang digunakan menguntungkan jika dikaitkan dengan informasi atau data yang tersedia. Jika data historis dengan pola musiman diketahui, maka peramalan harus menggunakan metode variasi musiman setahun sebelumnya. Pola data menunjukkan pola hubungan antar variabel, sehingga harus digunakan metode kausal. [14]

Model EOQ adalah salah satu teknik yang paling banyak digunakan sebagai teknik ukuran lot . EOQ lebih mudah digunakan jika jumlah permintaan diketahui, cukup konstan dan diketahui biaya penyimpanan di perusahaan, namun dengan menggunakan metode EOQ, perusahaan dapat meminimalkan biaya pengiriman yang dikeluarkan karena jumlah pesanan menggunakan rata-rata[15]

Dari uraian diatas maka perumusan masalah penelitian ini adalah Bagaimana menentukan teknik lotting yang optimal untuk pendistribusian produk air minum dalam kemasan dengan menggunakan metode Distribution Requirement Planning,.Tujuan penelitiannya adalah Menentukan teknik lotting yang optimal untuk pendistribusian produk air minum dalam kemasan dengan menggunakan metode Distribution Requirement Planning.

\section{METODE}

\section{Tahap Awal Penelitian}

Implementasi Metode Distribution Requirement Planning dalam Pengoptimalan Pendistribusian Produk Air Minum dalam Kemasan/ Nur Laila Handayani, Yusri Nadya, Dwi Maulana

Peer reviewed under responsibili of Universitas Muhammadiyah Sidoarjo.

(C) 2021 Universitas Muhammadiyah Sidoarjo. All Right reserved. This is an open access article

under the CC BY licence(http://creativecommons.org/licences/by/4.0/ ) 
Prozima : Vol. 5, No. 2, Desember 2021, 73-85

E.-ISSN. 2541-5115

Journal Homepage: http://ojs.umsida.ac.id/index.php/prozima

DOI Link: http://doi.org/10.21070/prozima.v5i2.1531

Article DOI: http://doi.org/10.21070/prozima.v5i2.1531

Tahap awal penelitian merupakan tahap pengumpulan informasi untuk proses identifikasi, merumuskan dan menentukan tujuan dari proses pemecahan masalah dengan tahap mempertimbangkan pengetahuan dan literatur yang ada. Adapun tahap penelitian awal sebagai berikut:

Lokasi Penelitian

Lokasi Penelitian iniakan dilaksanakan CV Athaya Mineral Langsa

\section{Survei Awal Penelitian}

Pada survei awal dilakukan pada pendistribusian air minum dalam kemasan Tari CV Athaya Mineral Langsa. Objek yang diamati adalah pendistribusian produk air minum dalam kemasan Tari Gelas, Tari Botol Kecil, Tari Botol Sedang, dan Tari Galon.

Penetapan Obyek Penelitian

Penelitian ini dilakukan pendistribusian produk air minum dalam kemasan Tari Gelas, Tari Botol Kecil, Tari Botol Sedang, dan Tari Studi ini dilakukan secara langsung di gudang PT. JC saat jam kerja dengan melihat proses manual material handling.

\section{Pengumpulan Data}

Pengumplan data penelitian dilakukan dengan mengambil data primer yaitu data produksi, Bill of Distribution, Data lead time, Data persediaan. Selain data primer juga dilakukan pengambilan data sekunder yaitu Jenis dan harga produk, Data historis pemesanan dan penjualan, jarak tempuh dari perusahaan menuju retail, harga telepon dan bahan bakar kendaraan, konsep Bullwhip Effect, Fishbone Diagram, Forecasting, dan Distribution Requirement Planning.

\section{Pengolahan Data}

Tahapan pengolahan yang akan digunakan untuk melakukan pengolahan data dalam penelitian yaitu sebagai berikut menghitung nilai bullwhip effect, fishbone diagram, peramalan (forecasting), perhitungan DRP (Distribution Requirement Planning)

\section{Pembahasan}

Pada tahap ini dilakukan analisa terhadap data-data yang telah diolah terkait berbagai hal yang terjadi setelah dilakukan pengolahan data. Data-data yang dianalisa dalam penelitian ini ialah dimulai dari menghitung nilai bullwhip effect serta mengidentifikasi faktor penyebab, lalu penentuan metode peramalan data penjualan berdasarkan hasil MAD, MSE dan MAPE terkecil dengan menggunakan software POM QM. Kemudian perhitungan rencana pemesanan yang dilakukan dengan metode Economic Order Quantity (EOQ).

\section{Hasil Dan Pembahasan}

Dalam penelitian ini akan dilakukan 3 perhitungan bullwhip effect selanjutnya disebut (BE) dari agregasi data permintaan dan data pemesanan. Ketiga perhitungan BE tersebut adalah pertama perhitungan bullwhip effect $(\omega 1)$ yaitu permintaan dan pemesanan untuk setiap produk pada setiap retail, kedua perhitungan bullwhip effect $(\omega 2)$ yaitu permintaan dan pemesanan untuk setiap produk pada seluruh retail, ketiga bullwhip effect ( $\omega 3)$ yaitu permintaan dan pemesanan untuk seluruh produk pada setiap retail.

Perhitungan Bullwhip Effect $(\omega 1, \omega 2, \omega 3)$

Bullwhip Effect $(\omega 1)$

$\overline{\bar{X}}$ order $\quad=\frac{\sum x i}{n}$

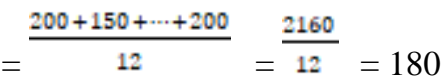

$\sigma$ order $\quad=\sqrt{\frac{\sum(x \hat{i}-\Omega)^{2}}{(n-1)}}$

$$
=\sqrt{\frac{6000,00}{11}}=23,35
$$

Implementasi Metode Distribution Requirement Planning dalam Pengoptimalan Pendistribusian Produk Air Minum dalam Kemasan/ Nur Laila Handayani, Yusri Nadya, Dwi Maulana

Peer reviewed under responsibili of Universitas Muhammadiyah Sidoarjo.

(C) 2021 Universitas Muhammadiyah Sidoarjo. All Right reserved. This is an open access article under the CC BY licence(http://creativecommons.org/licences/by/4.0/ ) 


$$
\begin{aligned}
& \mathrm{CV}(\text { order }) \quad=\sigma(\text { order }) / \overline{\bar{X}}_{(\text {order })} \\
& =23,35 / 180,00=0,13 \\
& \bar{X}_{\text {demand }}=\frac{\sum x \mathrm{i}}{n} \quad=\frac{197+144+\cdots+169}{12} \\
& =\frac{2027}{12} \quad=168,92 \\
& \sigma \text { demand } \quad=\sqrt{\frac{\sum(\mathrm{xi}-\Omega)^{2}}{(n-1)}}=\sqrt{\frac{2789_{2}, 92}{11}}=15,92 \\
& \mathrm{CV}(\text { demand }) \quad=\sigma(\text { demand }) /{ }^{\bar{X}}(\text { demand }) . . \\
& =15,92 / 168,92=0,09 \\
& \mathrm{BE}=\mathrm{CV} \text { (order) / CV (demand). } \\
& =0,13 / 0,09=1,38
\end{aligned}
$$

\begin{tabular}{|c|c|c|c|c|}
\hline & & & NILAI & KETERANGAN \\
\hline & & Tari Gelas & 1,38 & $\mathrm{BE}$ \\
\hline & 8 & Tari Botol Kecil & 0,87 & TIDAK BE \\
\hline & $\stackrel{\sim}{=}$ & Tari Botol Sedang & 0,77 & TIDAK BE \\
\hline & 2 & Tari Galon & 0,85 & TIDAK BE \\
\hline & & Tari Gelas & 2,26 & $\mathrm{BE}$ \\
\hline Perhitungan & 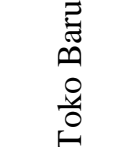 & Tari Botol Kecil & 1,18 & $\mathrm{BE}$ \\
\hline Bullwhip Effect & $\widetilde{\widetilde{Z}}$ & Tari Botol Sedang & 1,43 & $\mathrm{BE}$ \\
\hline produk pada & & Tari Galon & 0,97 & TIDAK BE \\
\hline & & Tari Gelas & 1,70 & $\mathrm{BE}$ \\
\hline & $\overrightarrow{7}$ & Tari Botol Kecil & 1,25 & $\mathrm{BE}$ \\
\hline & $\widetilde{\Xi}$ & Tari Botol Sedang & 0,94 & TIDAK BE \\
\hline & 2 & Tari Galon & 1,42 & $\mathrm{BE}$ \\
\hline & & Tari Gelas & 1,52 & $\mathrm{BE}$ \\
\hline & 疋 & Tari Botol Kecil & 0,82 & TIDAK BE \\
\hline & $\bar{n}$ & Tari Botol Sedang & 1,07 & $\mathrm{BE}$ \\
\hline
\end{tabular}

Tabel 2. Rekapitulasi Perhitungan Bullwhip Effect

Implementasi Metode Distribution Requirement Planning dalam Pengoptimalan Pendistribusian Produk Air Minum dalam Kemasan/ Nur Laila Handayani, Yusri Nadya, Dwi Maulana

Peer reviewed under responsibili of Universitas Muhammadiyah Sidoarjo. 
Prozima : Vol. 5, No. 2, Desember 2021, 73-85

E.-ISSN. 2541-5115

Journal Homepage: http://ojs.umsida.ac.id/index.php/prozima

DOI Link: http://doi.org/10.21070/prozima.v5i2.1531

Article DOI: http://doi.org/10.21070/prozima.v5i2.1531

\begin{tabular}{|c|c|c|c|}
\hline \multirow{5}{*}{ 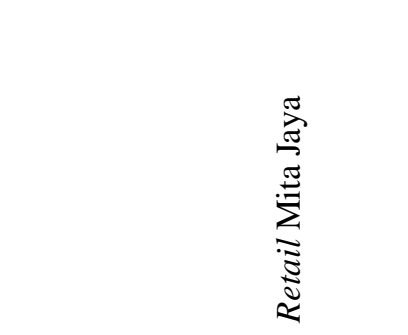 } & Tari Galon & 0,92 & TIDAK BE \\
\hline & Tari Gelas & 1,58 & $\mathrm{BE}$ \\
\hline & Tari Botol Kecil & 0,89 & TIDAK BE \\
\hline & Tari Botol Sedang & 1,30 & $\mathrm{BE}$ \\
\hline & Tari Galon & 1,03 & $\mathrm{BE}$ \\
\hline \multirow{4}{*}{$\begin{array}{c}\text { Perhitungan Bullwhip Effect } \\
(\omega 2) \text { setiap produk pada } \\
\text { seluruh retail }\end{array}$} & Tari Gelas & 1,005 & $\mathrm{BE}$ \\
\hline & Tari Botol Kecil & 0,981 & TIDAK BE \\
\hline & Tari Botol Sedang & 0,961 & TIDAK BE \\
\hline & Tari Galon & 0,980 & TIDAK BE \\
\hline \multirow{5}{*}{$\begin{array}{c}\text { Perhitungan Bullwhip Effect } \\
(\omega 3) \text { seluruh produk pada } \\
\text { setiap retail }\end{array}$} & Retail Kede Osa & 1,001 & $\mathrm{BE}$ \\
\hline & Retail Toko Baru & 1,002 & $\mathrm{BE}$ \\
\hline & Retail Ari JP & 0,996 & TIDAK BE \\
\hline & Retail Simpang Remi & 1,001 & $\mathrm{BE}$ \\
\hline & Retail Mita Jaya & 0,9999 & TIDAK BE \\
\hline
\end{tabular}

Keterangan : produk Tari Gelas pada Retail Kede Osa mengalami Bullwhip Effect karena nilai Bullwhip Effect $>1$

Dari hasil perhitungan diatas peneliti memilih perhitungan bullwhip effect ( $\omega 1)$ dikarenakan pada perhitungan ini peneliti dapat melihat dengan jelas produk apa saja yang mengalami bullwhip effect dan di retail mana saja yang mengalami bullwhip effect agar kemudian peneliti dapat membuat dan menyusun rencana pemesanan untuk periode selanjutnya agar tidak lagi terjadi bullwhip effect.

\section{Indetifikasi Penyebab Bullwhip Effect}

Identifikasi penyebab bullwhip effect dilakukan dengan menggunakan 2 tahap yaitu dengan menganalisanya $5 \mathrm{~W}+1 \mathrm{H}$ dan selanjutnya pembuatan fishbone diagram.

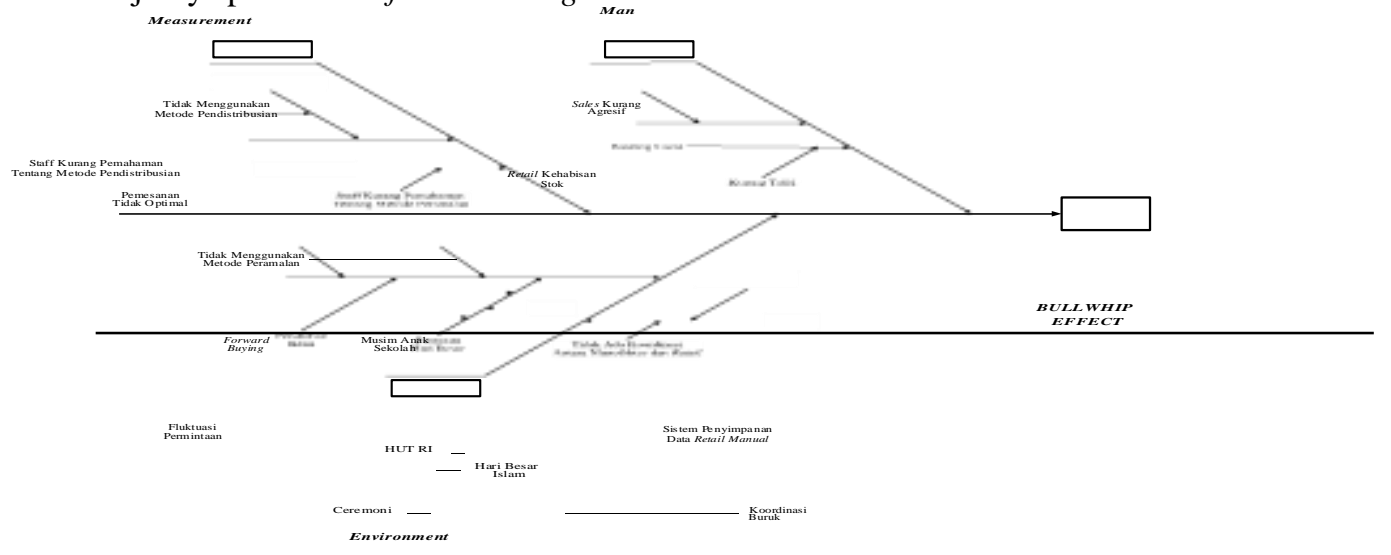

Gambar 1. Fishbone Diagram Penyebab Bullwhip Effect

Dari hasil wawancara dengan pihak perusahaan, distributor, dan retail didapatkan masalah yang paling krusial adalah masalah tidak diterapkannya metode peramalan dan juga metode pendistribusian. Usulan perbaikan

Implementasi Metode Distribution Requirement Planning dalam Pengoptimalan Pendistribusian Produk Air Minum dalam Kemasan/ Nur Laila Handayani, Yusri Nadya, Dwi Maulana

Peer reviewed under responsibili of Universitas Muhammadiyah Sidoarjo. 
yang dapat dilakukan adalah dengan perbaikan sistem pemesanan dan pendistribusian produk dengan penerapan metode Distribution Requirement Planning. Metode ini dapat mencegah terjadinya fluktuasi permintaan, retail tidak perlu lagi melakukan forward buying, dan juga dapat meningkatkan koordinasi antara manufaktur, distributor, dan retail.

\section{Hasil peramalan}

Peneliti melakukan peramalan jangka pendek yaitu untuk 3 bulan kedepan, untuk proses perhitungan hasil ramalan peneliti menggunakan bantuan shoftware yaitu POM QM for Windows.

\section{Economic Order Quantity}

Selama ini PT. Athaya Mineral dalam menentukan order quantity menggunakan metode lot for lot yaitu besar pengiriman produk disesuaikan dengan jumlah permintaan sehingga menyebabkan besarnya biaya pendistribusian produk. Dengan metode EOQ, perhitungan order quantity dilakukan untuk mengetahui jumlah optimum yang akan dikirimkan untuk setiap kali pemesanan pada masing-masing retail sehingga perusahaan dapat meminimumkan biaya transportasi.

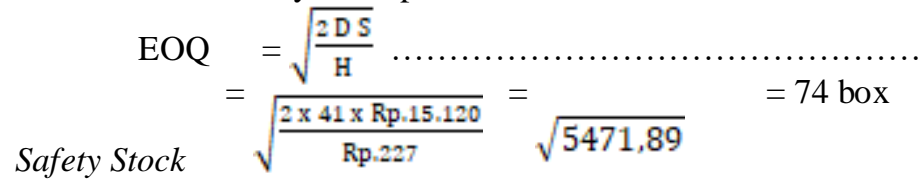

Safety stock merupakan suatu acuan untuk melakukan pemesanan kembali guna memenuhi Rencana Induk Penjualan (RIP). Dalam pengembangan sistem DRP ini, perkiraan safety stock dilakukan dengan cara sederhana dengan menganggap permintaan normal selama lead time distribusi dan service level yang digunakan adalah $99,74 \%$. Contoh perhitungan standar deviasi untuk retail kede osa produk tari gelas dengan menggunakan rumus

$$
\begin{aligned}
\bar{X} & =\frac{\sum X i}{n}=\frac{\frac{157+160+162}{3}}{\frac{479}{3}=159,7 \text { box }} \\
& =\sqrt{\frac{\sum(X i-\bar{X})^{2}}{(n-1)}}=\sqrt{\frac{12,52}{2}}=2,50 \\
\mathrm{~s} & =\sqrt{\mathrm{SS}}=\mathrm{s} \mathrm{x} \mathrm{z} \\
& =2,50 \times 2,79=7 \text { box }
\end{aligned}
$$

\section{Rekapitulasi Input DRP}

Kemudian seluruh perhitungan input distribution requirement planning (DRP) di rekap kedalam sebuah tabel untuk mempermudan pembacaan. Tabel rekapitulasi input DRP dapat dilihat pada tabel 3:

Tabel 3. Rekapitulasi Input Distribution Requirement Planning

\begin{tabular}{ccccccc}
\hline Retail & Produk & $\begin{array}{c}\text { Biaya } \\
\text { Pemesanan }\end{array}$ & $\begin{array}{c}\text { Biaya } \\
\text { Penyimpanan }\end{array}$ & EOQ & $\begin{array}{c}\text { Safety } \\
\text { Stock }\end{array}$ & Persediaan \\
\hline Kede Osa & Tari Gelas & Rp. 15.120 & Rp. 227 & 74 box & 7 box & 104 box \\
Toko Baru & Tari Gelas & Rp. 15.600 & Rp. 227 & 120 box & 3 box & 359 box
\end{tabular}

Implementasi Metode Distribution Requirement Planning dalam Pengoptimalan Pendistribusian Produk Air Minum dalam Kemasan/ Nur Laila Handayani, Yusri Nadya, Dwi Maulana

Peer reviewed under responsibili of Universitas Muhammadiyah Sidoarjo. 


\begin{tabular}{|c|c|c|c|c|c|c|}
\hline & & \multicolumn{5}{|c|}{$\begin{array}{l}\text { Prozima : Vol. 5, No. 2, Desember 2021, 73-85 } \\
\text { E.-ISSN. 2541-5115 } \\
\text { Journal Homepage: } \text { http://ojs.umsida.ac.id/index.php/prozima } \\
\text { DOI Link: http://doi.org/10.21070/prozima.v5i2.1531 } \\
\text { Article DOI: http://doi.org/10.21070/prozima.v5i2.1531 }\end{array}$} \\
\hline \multirow{5}{*}{ Ari JP } & Tari Btl Kecil & Rp. 15.600 & Rp. 455 & 33 box & 3 box & 30 box \\
\hline & Tari Bt1 Sedang & Rp. 15.600 & Rp. 508 & 41 box & 1 box & 27 box \\
\hline & Tari Gelas & Rp. 16.560 & Rp. 227 & 143 box & 18 box & 411 box \\
\hline & Tari Btl Kecil & Rp. 16.560 & Rp. 455 & 15 box & 2 box & 6 box \\
\hline & Tari Galon & Rp. 16.560 & Rp. 300 & 23 galon & 2 galon & 20 galon \\
\hline \multirow{3}{*}{$\begin{array}{c}\text { Simpang } \\
\text { KeIIII }\end{array}$} & Tari Gelas & Rp. 17.600 & Rp. 227 & 96 box & 21 box & 238 box \\
\hline & Tari Bt1 Sedang & Rp. 17.600 & Rp. 508 & 25 box & 1 box & 28 box \\
\hline & Tari Gelas & Rp. 17.040 & Rp. 227 & 165 box & 5 box & 640 box \\
\hline \multirow[t]{2}{*}{ Mita Jaya } & Tari Bt1 Sedang & Rp. 17.040 & Rp. 508 & 25 box & 1 box & 33 box \\
\hline & Tari Galon & Rp. 17.040 & Rp. 300 & 18 galon & 1 galon & 6 galon \\
\hline
\end{tabular}

Perbandingan Teknik Lotting

Berikut adalah perbandingan biaya distribusi termurah metode Distribution Requirement Planning (DRP) antara menggunakan teknik lotting Economic Order Quantity (EOQ) dan Lot For Lot (LFL) dapat dilihat pada Tabel 4.

Tabel 4.Perbandingan Biaya Distribusi Antara EOQ Dan LFL

\begin{tabular}{|c|c|c|c|c|}
\hline Retail & Produk & $\begin{array}{c}\text { Economic Order } \\
\text { Quantity }\end{array}$ & Lot for Lot & $\begin{array}{c}\text { Metode Lotting } \\
\text { Termurah }\end{array}$ \\
\hline \multirow[t]{2}{*}{ Kede Osa } & Tari Gelas & Rp. 233.696 & Rp. 254.314 & $\begin{array}{c}\text { Economic Order } \\
\text { Quantity }\end{array}$ \\
\hline & Tari Gelas & Rp. 428.762 & Rp. 417.336 & Lot for Lot \\
\hline I'oko Baru & $\begin{array}{l}\text { Tari Botol } \\
\text { Kecil }\end{array}$ & Kp. 215.096 & Kp. 261.690 & $\begin{array}{c}\text { Economic Order } \\
\text { Quantity }\end{array}$ \\
\hline \multirow{3}{*}{ Ari JP } & $\begin{array}{l}\text { Tari Botol } \\
\text { Sedang }\end{array}$ & Rp. 119.065 & Rp. 32.480 & Lot for Lot \\
\hline & Tari Gelas & Rp. 616.359 & Rp. 657.150 & $\begin{array}{c}\text { Economic Order } \\
\text { Quantity }\end{array}$ \\
\hline & $\begin{array}{l}\text { Tari Botol } \\
\text { Kecil }\end{array}$ & Rp. 99.727 & Rp. 201.270 & $\begin{array}{c}\text { Economic Order } \\
\text { Quantity }\end{array}$ \\
\hline \multirow{3}{*}{$\begin{array}{l}\text { Simpang } \\
\text { Remi }\end{array}$} & Tari Galon & Rp. 85.749 & Rp. 177.540 & $\begin{array}{c}\text { Economic Ordeı } \\
\text { Quantity }\end{array}$ \\
\hline & Tari Gelas & Rp. 379.456 & Rp. 410.860 & $\begin{array}{c}\text { Economic Order } \\
\text { Quantity }\end{array}$ \\
\hline & $\begin{array}{l}\text { Tari Botol } \\
\text { Sedang }\end{array}$ & Rp. 165.140 & Rp. 192.403 & $\begin{array}{l}\text { Economic Order } \\
\text { Quantity }\end{array}$ \\
\hline
\end{tabular}

Implementasi Metode Distribution Requirement Planning dalam Pengoptimalan Pendistribusian Produk Air Minum dalam Kemasan/ Nur Laila Handayani, Yusri Nadya, Dwi Maulana

Peer reviewed under responsibili of Universitas Muhammadiyah Sidoarjo.

(C) 2021 Universitas Muhammadiyah Sidoarjo. All Right reserved. This is an open access article

under the CC BY licence(http://creativecommons.org/licences/by/4.0/ ) 
Prozima : Vol. 5, No. 2, Desember 2021, 73-85

E.-ISSN. 2541-5115

Journal Homepage: http://ojs.umsida.ac.id/index.php/prozima

DOI Link: http://doi.org/10.21070/prozima.v5i2.1531

Article DOI: http://doi.org/10.21070/prozima.v5i2.1531

$\begin{array}{ccccc}\text { Mita Jaya } & \text { Tari Gelas } & \text { Rp. 619.981 } & \text { Rp. 730.121 } & \begin{array}{c}\text { Economic Order } \\ \text { Quantity }\end{array} \\ \begin{array}{c}\text { Tari Botol } \\ \text { Sedang }\end{array} & \text { Rp. } 166.664 & \text { Rp. } 220.350 & \begin{array}{c}\text { Economic Order } \\ \text { Quantity }\end{array} \\ \text { Tari Galon } & \text { Rp. } 92.932 & \text { Rp. 200.040 } & \begin{array}{c}\text { Economic Order } \\ \text { Quantity }\end{array}\end{array}$

\section{Pembahasan Perhitungan Bullwhip Effect}

Berdasarkan pengolahan data dan perhitungan bullwhip effect yang telah dilakukan didapatkan nilai bullwhip effect yang terjadi pada CV Athaya Mineral, apabila nilai BE $>1$ artinya terjadi bullwhip effect dan sebaliknya apabila nilai BE $<1$ artinya tidak terjadi bullwhip effect. Dalam penelitian ini terdapat 3 perhitungan bullwhip effect pada 5 retail yang ada dikota langsa dan pada 4 produk.

Pembahasan Identifikasi Penyebab Bullwhip Effect

Identifikasi penyebab bullwhip effect dilakukan 2 tahap yaitu dengan melakukan pertanyaan $5 \mathrm{w}+1 \mathrm{~h}$ selanjutnya dibuatkan fishbone diagram berdasarkan analisis tersebut.Perusahaan tidak menggunakan peramalan penjualan, hanya mengandalkan distributor untuk pemasaran. Perusahaan tidak menggunakan metode pendistribusian, hanya mengandalkan distributor untuk pemasaran dan pengiriman sesuai pemesanan dari retail. Koordinasi yang buruk antara perusahaan dan retail, perusaan menggunakan pihak distributor untuk mengetahui pesanan dari setiap retail.

\section{Fishbone Diagram}

Dari fishbone diagram dikelompokan dalam 3 katagori yaitu man (kesalahan manusia), environment (lingkungan), measurement (pengukuran). Katagori pertama man, merupakan kelompok penyebab yang disebabkan oleh faktor kesalahan pada manusia atau human error. Adapun penyebab nya antara lain:

1. Retail kehabisan stok, hal ini disebabkan lagi oleh sales yang kurang agresif dalam menawarkan produk.

2. Barang cacat, hal ini disebabkan oleh kurang telitinya karyawan dalam memproduksi produk dan pengepakan

Katagori kedua environment, merupakan kelompok penyebab yang disebabkan oleh faktor lingkungan kerja baik didalam maupun diluar perusahaan, kondisi lapangan, dan juga pelaku supply chain. Adapun penybab nya antara lain:

1. Koordinasi buruk, hal ini terjadi karena tidak adanya komunikasi langsung antar manufaktur dan retail, disebabkan juga karena sistem penyimpanan data retail masih manual.

2. Fluktuasi permintaan, hal ini terjadi karna banyak penybab yaitu forward buying, perubahan iklim, musim anak sekolah, perayaan hari besar.

Katagori ketiga measurement, merupakan kelompok penyebab yang disebabkan oleh faktor kesalahan perhitungan atau hal sejenisnya. Adapun penyebabnya antara lain:

1. Tidak menggunakan metode peramalan, disini perusahaan tidak menerapkan metode peramalan untuk penjualannya, penyebabnya karena staff kurang pemahaman tentang metode peramalan.

2. Pemesanan tidak optimal, hal ini disebabkan karena perusahaan tidak menerapkan metode pendistribusian, dan juga staff kurang memahami tentang metode pendistribusian.

\section{Pembahasan Perhitungan Input DRP}

\section{Rencana Induk Penjualan}

Pembahasan rencana induk penjualan ditentukan dari hasil peramalan dari metode peramalan dengan nilai MAD, MSE dan MAPE terkecil. Kemudian dari hasil peramalan tersebut dibagi menjadi empat, hal ini dilakukan karena jadwal induk penjualan disusun berdasarkan periode mingguan dengan asumsi setiap bulan terdapat empat minggu, maka data peramalan terlebih dahulu dikonversikan kedalam periode mingguan.

\section{Biaya - biaya}

Biaya biaya yang digunakan dalam perhitungan distribution requirement planning adalah biaya pemesanan dan biaya penyimpanan. Dalam pemesanan biaya yang dikeluarkan adalah biaya nota orderan yang mana setiap kali

Implementasi Metode Distribution Requirement Planning dalam Pengoptimalan Pendistribusian Produk Air Minum dalam Kemasan/ Nur Laila Handayani, Yusri Nadya, Dwi Maulana

Peer reviewed under responsibili of Universitas Muhammadiyah Sidoarjo.

(C) 2021 Universitas Muhammadiyah Sidoarjo. All Right reserved. This is an open access article under the CC BY licence(http://creativecommons.org/licences/by/4.0/ ) 
Prozima : Vol. 5, No. 2, Desember 2021, 73-85

E.-ISSN. 2541-5115

Journal Homepage: http://ojs.umsida.ac.id/index.php/prozima

DOI Link: http://doi.org/10.21070/prozima.v5i2.1531

Article DOI: http://doi.org/10.21070/prozima.v5i2.1531

order retail akan mengeluarkan biaya untuk berkas-berkas, dari penelitian diasumsikan biaya nota yang dikeluarkan setiap retail adalah sebesar Rp. 2.000,00. dalam pemesanan juga mengeluarkan biaya telepon, yang mana diasumsikan setiap kali order retail akan melakukan telepon selama 10 menit dan menggunakan kartu prabayar telkomsel dengan harga permenit pulsa nya adalah Rp. 1.184,00 per menit . Lalu dalam biaya pemesanan lain adalah biaya pengiriman, biaya pengiriman ini dihitung berdasarkan jarak perusahaan menuju retail dengan menggunakan asumsi bahwa 1 liter bahan bakar solar dapat menempuh jarak $12 \mathrm{~km}$ dan harga perliter solar nya adalah $\mathrm{Rp}$.

9.600,00. Biaya penyimpanan di CV Athaya Mineral dengan menerapkan biaya 7\% dari harga produk.

3. Order Quantity

Selama ini PT. Athaya Mineral dalam menentukan order quantity menggunakan metode lot for lot yaitu besar pengiriman produk disesuaikan dengan jumlah permintaan sehingga menyebabkan besarnya biaya pendistribusian produk. Dengan metode EOQ, perhitungan order quantity dilakukan untuk mengetahui jumlah optimum yang akan dikirimkan untuk setiap kali pemesanan pada masing-masing retail sehingga perusahaan dapat meminimumkan biaya transportasi.

4. Safety stock

Dalam perencanaan sistem Distribution Resource Planning ini perkiraan safety stock dilakukan dengan cara sederhana dengan menganggap permintaan normal selama lead time distribusi dan tingkat pelayanan yang didapatkan adalah 99,957\%.

\section{KESIMPULAN}

Berdasarkan pengolahan data yang dilakukan didapatkan teknik lotting terbaik dengan biaya termurah dalam biaya penyimpan dan pengiriman produk. Untuk biaya produk Tari Gelas retail Kede Osa dengan menggunakan teknik lotting EOQ dengan total biaya Rp. 233.696. Untuk produk Tari Gelas retail Toko Baru dengan menggunakan teknik lotting LFL dengan total biaya Rp. 417.336. Untuk produk Tari Botol Kecil retail Toko Baru dengan menggunakan teknik lotting EOQ dengan total biaya Rp. 215.096. Untuk produk Tari Botol Sedang retail Toko Baru menggunakan teknik lotting LFL dengan total biaya Rp. 32.480. Untuk produk Tari Gelas retail Ari JP menggunakan teknik lotting EOQ dengan total biaya Rp. 616.359. Untuk produk Tari Botol Kecil retail Ari JP menggunakan teknik lotting EOQ dengan total biaya Rp. 99.727. Untuk produk Tari Galon retail Ari JP menggunakan teknik lotting EOQ dengan total biaya Rp. 85.749. Untuk produk Tari Gelas retail Simpang Remi menggunakan teknik lotting EOQ dengan total biaya Rp. 379.456. Untuk produk Tari Botol Sedang retail Simpang Remi menggunakan teknik lotting EOQ dengan total biaya Rp. 165.140. Untuk produk Tari Gelas retail Mita Jaya menggunakan teknik lotting EOQ dengan total biaya Rp. 619.981. Untuk produk Tari Botol Sedang retail Mita Jaya menggunakan teknik lotting EOQ dengan total biaya Rp. 166.664. Untuk produk Tari Galon retail Mita Jaya menggunakan teknik lotting EOQ dengan total biaya Rp. 92.932.

\section{DAFTAR PUSTAKA}

[1] M. Hakimah, R. R. Muhima, and A. Yustina, "Rancang Bangun Aplikasi Persediaan Barang dengan Metode Trend Projection," SimanteC, vol. 5, no. 1, pp. 37-48, 2015, [Online]. Available: http://neobis.trunojoyo.ac.id/simantec/article/download/1023/899.

[2] v Gasper, "Production Planning And Inventory Control. Berdasarkan Pendekatan Sistem Terintegrasi MRP II \& JIT menuju Manufacturing 21.” 2012.

[3] S. Kasus, B. Terang, G. Gedangan, and D. Oleh, "Distribution requirement planning (drp)," vol. 3, no. 2, pp. $1-22,2010$.

[4] "Penerbit Guna Widya Supply Chain Management.pdf." .

[5] J. T. Industri, F. Teknik, and U. M. Malang, "Pengurangan Bullwhip Effect Dengan Metode," vol. 14, no. 2, pp. 292-298, 2015.

[6] M. Agustina and F. Oktasari, "Penerapan Metode DRP( Distribusi Requirement Planning ) Pada Sistem Informasi Distribusi LPG ( Studi Kasus : PT Bumi Sriwijaya Palembang )," Semin. Nas. Inform., vol. 2012, no. semnasIF, pp. 76-81, 2012.

[7] F. Munawaroh and W. F. Mahmudy, "kesinambungan kegiatan Distributor memasarkan produk ke berbagai daerah sehingga pemasaran produk menjadi luas. Semakin luas daerah pemasaran produk, maka produk tersebut akan semakin dikenal dan membawa keuntungan yang beasar bagi perusahaan sehingga k, $J$. Environ. Eng. Sustain. Technol., vol. 02, no. 02, pp. 89-96, 2015.

Implementasi Metode Distribution Requirement Planning dalam Pengoptimalan Pendistribusian Produk Air Minum dalam Kemasan/ Nur Laila Handayani, Yusri Nadya, Dwi Maulana

Peer reviewed under responsibili of Universitas Muhammadiyah Sidoarjo.

(C) 2021 Universitas Muhammadiyah Sidoarjo. All Right reserved. This is an open access article

under the CC BY licence(http://creativecommons.org/licences/by/4.0/ ) 
Prozima : Vol. 5, No. 2, Desember 2021, 73-85

E.-ISSN. 2541-5115

Journal Homepage: http://ojs.umsida.ac.id/index.php/prozima

DOI Link: http://doi.org/10.21070/prozima.v5i2.1531

Article DOI: http://doi.org/10.21070/prozima.v5i2.1531

[8] D. N. B. Sembiring, A. Y. Ridwan, and R. Aurachman, "Usulan Perencanaan Dan Pengendalian Aktivitas Distribusi Pulp Di PT XYZ Untuk Meningkatkan Kemampuan Pemenuhan Permintaan Setiap Distribution Center (DC) Menggunakan Metode Distribution Requirement Planning (DRP)," eProceedings Eng., vol. 4, no. 3, pp. 4426-4435, 2017.

[9] M. I. Mustofa and F. N. Hakim, "Rule Based Dan Safety Stock Utuk Monitoring," pp. 27-31, 2018.

[10] Tri Susilo, "Analisa Bullwhip Effect pada Supply Chain (studi kasus pada pt . Istana Cipta Sembada Sidoarjo)," J. Penelit. Ilmu Tek., vol. 8, no. 2, pp. 64-73, 2008.

[11] E. W. A. Belo, Armandina Maria, Joko Susetyo, "Jurnal Rekavasi," J. REKAVASI, vol. 4, no. 2, pp. 60-118, 2016.

[12] R. A. Mahaji Puteri and M. Prasetyawati, "Analisa Penyebab Kegagalan Kemasan Cup Minuman Instan Aloe Vera," Pros. Semin. Nas. Teknoka, vol. 3, no. 2502, p. 27, 2019, doi: 10.22236/teknoka.v3i0.2909.

[13] S. Wardah and Iskandar, "KEMASAN BUNGKUS ( Studi Kasus : Home Industry Arwana Food Tembilahan )," J. Tek. Ind., vol. 9, no. 3, pp. 135-142, 2016.

[14] A. Purwanto and S. Hanief, "Teknik Peramalan Dengan Double Exponential Smoothing Pada Distributor Gula," J. Teknol. Inf. dan Komput., vol. 3, no. 1, pp. 362-366, 2017, doi: 10.36002/jutik.v3i1.238.

[15] I. O. Countermeasures, “梁发超 1， 刘洔苑 2， 起尧星 ※3,” vol. 3, no. 0, pp. 377-388, 2017.

Implementasi Metode Distribution Requirement Planning dalam Pengoptimalan Pendistribusian Produk Air Minum dalam Kemasan/ Nur Laila Handayani, Yusri Nadya, Dwi Maulana

Peer reviewed under responsibili of Universitas Muhammadiyah Sidoarjo.

(C) 2021 Universitas Muhammadiyah Sidoarjo. All Right reserved. This is an open access article

under the CC BY licence(http://creativecommons.org/licences/by/4.0/ ) 